\title{
Endoscopic third ventriculostomy in children: prospective, multicenter results from the Hydrocephalus Clinical Research Network
}

\author{
Abhaya V. Kulkarni, MD, PhD, ${ }^{1}$ Jay Riva-Cambrin, MD, MSc, ${ }^{2}$ Richard Holubkov, $\mathrm{PhD},{ }^{3}$ \\ Samuel R. Browd, MD, PhD, ${ }^{4}$ D. Douglas Cochrane, MD, ${ }^{5}$ James M. Drake, FRCSC, ${ }^{1}$ \\ David D. Limbrick, MD, PhD, ${ }^{6}$ Curtis J. Rozzelle, MD, ${ }^{10}$ Tamara D. Simon, MD, MSPH, ${ }^{4}$ \\ Mandeep S. Tamber, MD, PhD, ${ }^{7}$ John C. Wellons III, MD, MSPH, ${ }^{8}$ William E. Whitehead, MD, ${ }^{9}$ and \\ John R. W. Kestle, MD, MSc, ${ }^{3}$ for the Hydrocephalus Clinical Research Network \\ ${ }^{1}$ Hospital for Sick Children, University of Toronto, Ontario; ${ }^{2}$ Alberta Children's Hospital, University of Calgary, Alberta; ${ }^{5 B C}$ \\ Children's Hospital, University of British Columbia, Vancouver, British Columbia, Canada; ${ }^{3}$ rimary Children's Medical Center, \\ Salt Lake City, Utah; ${ }^{4}$ Seattle Children's Hospital, Seattle, Washington; ${ }^{6}$ St. Louis Children's Hospital, St. Louis, Missouri;

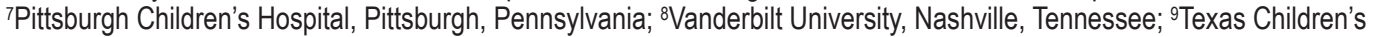 \\ Hospital, Houston, Texas; and ${ }^{10}$ Children's Hospital of Alabama, Birmingham, Alabama
}

OBJECTIVE Endoscopic third ventriculostomy (ETV) is now established as a viable treatment option for a subgroup of children with hydrocephalus. Here, the authors report prospective, multicenter results from the Hydrocephalus Clinical Research Network (HCRN) to provide the most accurate determination of morbidity, complication incidence, and efficacy of ETV in children and to determine if intraoperative predictors of ETV success add substantially to preoperative predictors.

METHODS All children undergoing a first ETV (without choroid plexus cauterization) at 1 of 7 HCRN centers up to June 2013 were included in the study and followed up for a minimum of 18 months. Data, including detailed intraoperative data, were prospectively collected as part of the HCRN's Core Data Project and included details of patient characteristics, ETV failure (need for repeat hydrocephalus surgery), and, in a subset of patients, postoperative complications up to the time of discharge.

RESULTS Three hundred thirty-six eligible children underwent initial ETV, $18.8 \%$ of whom had undergone shunt placement prior to the ETV. The median age at ETV was 6.9 years (IQR 1.7-12.6), with $15.2 \%$ of the study cohort younger than 12 months of age. The most common etiologies were aqueductal stenosis (24.8\%) and midbrain or tectal lesions $(21.2 \%)$. Visible forniceal injury (16.6\%) was more common than previously reported, whereas severe bleeding (1.8\%), thalamic contusion $(1.8 \%)$, venous injury $(1.5 \%)$, hypothalamic contusion $(1.5 \%)$, and major arterial injury $(0.3 \%)$ were rare. The most common postoperative complications were CSF leak (4.4\%), hyponatremia (3.9\%), and pseudomeningocele (3.9\%). New neurological deficit occurred in $1.5 \%$ cases, with $0.5 \%$ being permanent.

One hundred forty-one patients had documented failure of their ETV requiring repeat hydrocephalus surgery during follow-up, 117 of them during the first 6 months postprocedure. Kaplan-Meier rates of 30-day, 90-day, 6-month, 1-year, and 2 -year failure-free survival were $73.7 \%, 66.7 \%, 64.8 \%, 61.7 \%$, and $57.8 \%$, respectively. According to multivariate modeling, the preoperative ETV Success Score (ETVSS) was associated with ETV success $(p<0.001)$, as was the intraoperative ability to visualize a "naked" basilar artery $(p=0.023)$.

CONCLUSIONS The authors' documented experience represents the most detailed account of ETV results in North America and provides the most accurate picture to date of ETV success and complications, based on contemporaneously collected prospective data. Serious complications with ETV are low. In addition to the ETVSS, visualization of a naked basilar artery is predictive of ETV success.

http://thejns.org/doi/abs/10.3171/2016.4.PEDS163

KEY WORDS pediatric; hydrocephalus; endoscopy; third ventriculostomy

ABBREVIATIONS CPC = choroid plexus cauterization; CSF = cerebrospinal fluid; ETV = endoscopic third ventriculostomy; ETVSS = ETV Success Score; HCRN = Hydrocephalus Clinical Research Network; IVH = intraventricular hemorrhage.

SUBMITTED January 2, 2016. ACCEPTED April 4, 2016.

INCLUDE WHEN CITING Published online June 3, 2016; DOI: 10.3171/2016.4.PEDS163. 
$\mathrm{E}$ NDOSCOPIC third ventriculostomy (ETV) is now well established as an effective treatment for many children with hydrocephalus. Small and large case series on the procedure are well documented in the medical literature, but a paucity of multicenter prospective data remains. ${ }^{2,20}$ This absence of data has limited our ability to definitively answer important questions about ETV complications and efficacy. Especially lacking are accurate data regarding intraoperative events and the impact such events may have on ETV success. While the ETV Success Score (ETVSS $)^{15}$ has helped surgeons predict the success of the procedure based on preoperative factors, the identification of important intraoperative factors may further help surgeons in decision making and perhaps provide insight into the essential technical elements of an optimal ETV.

The Hydrocephalus Clinical Research Network (HCRN), a multicenter North American research collaborative, began in 2007, as part of its core data registry, a prospective study of ETV in children. This involved real-time, contemporaneous collection of data, including intraoperative details. In the current study, we present our first analysis of these data, aiming to answer 2 specific questions about ETV. First, what is the current morbidity, complication incidence, and efficacy of ETV in children treated at tertiary care centers in North America? Second, what are the predictors of successful ETV, and specifically, do intraoperative factors add substantially to established preoperative predictors? ${ }^{15}$ Our report specifically excludes children who underwent choroid plexus cauterization (CPC) in addition to ETV.

\section{Methods \\ Population}

All patients were 19 years old or younger with symptomatic hydrocephalus and were treated by pediatric neurosurgeons at specialized centers. During the period of patient accrual for this study, the patients were treated at 1 of 7 HCRN centers: Children's Hospital of Alabama, Birmingham, Alabama; Primary Children's Hospital, Salt Lake City, Utah; Seattle Children's Hospital, Washington; Children's Hospital of Pittsburgh, Pennsylvania; St. Louis Children's Hospital, Missouri; Texas Children's Hospital, Houston, Texas; Hospital for Sick Children, Toronto, Canada (see Appendix for further details regarding the HCRN). Data for all patients undergoing ETV were prospectively collected by the treating surgeons and trained, dedicated research coordinators at each center. For this analysis, procedures in which CPC was performed in addition to ETV were excluded. Data accrual began as early as 2008 at some centers, with a staggered start at other centers. All procedures performed up to June 2013 were included in our analysis to allow for at least 18 months of accurate follow-up to December 31, 2014. Data were stored centrally and securely at the Data Coordinating Center in Salt Lake City, Utah. Standardized audits of data accuracy are performed regularly to ensure data accuracy and timeliness. All data were anonymized, and data collection adhered to local research ethics protocols.

Specific baseline data collected included patient age; etiology of hydrocephalus (defined as aqueductal stenosis, brain tumor [supratentorial, infratentorial, or mid- brain], CSF infection, head injury, intraventricular hemorrhage [associated with prematurity or other spontaneous causes], myelomeningocele, encephalocele, posterior fossa cyst [for example, Dandy-Walker syndrome and variants], other intracranial cyst [for example, arachnoid cyst, porencephalic cyst], communicating congenital hydrocephalus, other congenital disorder [for example, schizencephaly, holoprosencephaly], and craniosynostosis); and previous hydrocephalus treatment.

Specific intraoperative data included duration of surgery; type(s) of endoscope used; degree of intraoperative bleeding (defined as none, mild [did not obstruct view totally], moderate [view totally obstructed but cleared within 2-3 minutes], or severe [took more than 5 minutes to return to a clear working condition]), degree of forniceal injury visualized (defined as follows: could not be assessed; no visible injury with fornix pristine; small, punctate contusions or subpial hemorrhage(s) but ependyma intact; large confluent contusions or subpial hemorrhage but ependyma intact; small breach of ependyma overlying the fornix; or frank tear of the fornix), major arterial injury, venous injury, thalamic contusion, hypothalamic contusion, and whether concurrent biopsy was performed.

Details of the creation of the third ventricle floor fenestration included whether fenestration of the third ventricle was abandoned; method of floor penetration and dilation; whether the third ventricle floor ballooned up after fenestration; whether any residual prepontine membranes were left unopened; if the scope could be guided through the ostomy; if a "naked" basilar artery could be visualized (that is, no residual membranes obstructing the view of the basilar artery); and the surgeon's intraoperative estimate of the diameter of the ostomy.

Endoscopic third ventriculostomy failure was defined as the need for repeat hydrocephalus surgery, as determined by the treating surgeon, with either repeat ETV or CSF shunt placement, or as death related to hydrocephalus management.

The ETVSS was calculated for each patient. ${ }^{15}$ This score uses the patient's age, etiology of hydrocephalus, and presence of a previous shunt to provide an estimated chance of ETV success at 6 months, ranging from $0 \%$ to $90 \%$. The ETVSS has been independently validated in multiple studies across North America, Europe or the United Kingdom, and elsewhere. ${ }^{1,3,5,7,8,16,18,24}$ In some cases, a definitive etiology for the hydrocephalus could not be identified. Although the ETVSS does include an etiology category for "other," for our analysis, we did not calculate an ETVSS for patients without a clearly defined etiology.

Data on early postoperative complications (up to the time of discharge from the hospital) were collected from early 2011 onwards and so were available on only a subset of the cohort. These data included new neurological deficit, seizure, brain hemorrhage, CSF leak, meningitis, pseudomeningocele, wound infection, and various medical complications (for example, hyponatremia, pneumonia, urinary tract infection, thromboembolic disorder, cardiac complications, and so forth).

\section{Statistical Analysis}

Survival curves were calculated using the Kaplan-Mei- 
er method for time to first ETV failure. We then tested the following variables to determine predictors of ETV success: the ETVSS (which accounts for the prognostic effects of age, etiology, and previous shunt), concurrent biopsy performed (yes vs no); degree of intraoperative bleeding (moderate to severe bleeding vs other); whether the third ventricle floor ballooned up after fenestration (yes vs no); whether any residual prepontine membranes were left unopened (yes vs no); if the scope could be guided through the ostomy (yes vs no); if a naked basilar artery could be visualized (yes vs no); and an estimate of the diameter of the ostomy (in $\mathrm{mm}$ ). We conducted 2 types of regression analyses to determine whether these variables were significant predictors of ETV success.

First, we performed survival analysis for time to ETV failure, beginning with appropriate univariate survival analysis (log-rank test for binary factors, Cox regression for continuous factors). The proportional-hazards assumption was confirmed for variables as required. Variables that were significant at $p<0.15$ were entered into a multivariate Cox regression model. Second, we repeated the univariate and multivariate analyses described above but instead used survival up to 6 months as the outcome. All analyses were performed with SAS statistical software (SAS Institute Inc.).

\section{Results}

The characteristics of the $336 \mathrm{ETV}$ patients are listed in Table 1. The median age at ETV was 6.9 years (IQR 1.7-12.6). The most common etiologies were aqueductal stenosis, midbrain tumor or lesion, and posterior fossa tumor. Intraoperative details are presented in Table 2. The median duration of surgery was 1.1 hours (range 0.3-6 hours). The median estimated diameter of the created ostomy was $5.0 \mathrm{~mm}$ (range $1.0-10.0 \mathrm{~mm}$ ).

Severe intraoperative injuries were rare (Table 2), but some degree of visible forniceal injury was relatively common (53 cases [16.6\%]). Details of the third ventricle floor fenestration are shown in Table 3. Ommaya reservoirs were used in 27 (8.7\%) of 311 cases with available information.

Information on postoperative complications was available in a subset of 204 patients (Table 4). The most common complications were CSF leak, hyponatremia, and pseudomeningocele.

During follow-up, 141 patients had documented failure of their ETV requiring repeat hydrocephalus surgery. Kaplan-Meier rates of 30-day, 90-day, 6-month, 1-year, and 2-year failure-free survival were $73.7 \%, 66.7 \%, 64.8 \%$, $61.7 \%$, and $57.8 \%$, respectively. Figure 1 shows the Kaplan-Meier survival curve for time to first ETV failure.

The ETVSS was determined for 334 patients, as an accurate etiology of hydrocephalus could not be defined in 2 patients. Among these 334 patients, the observed 6-month Kaplan-Meier success rate of $64.5 \%$ was $10 \%$ less than the average ETVSS of $74.8 \%$, which represents the predicted 6-month ETV success rate based on baseline patient prognostic factors.

In univariate survival analyses, the following 2 variables had associations with ETV success with a $\mathrm{p}<0.15$ : ETVSS ( $p<0.001$, Cox regression) and ability to view a naked basilar artery $(\mathrm{p}=0.013, \log$-rank test). When these
TABLE 1. Summary of characteristics in 336 patients who underwent ETV

\begin{tabular}{|c|c|}
\hline Variable & No. of Cases (\%) \\
\hline Previous shunt & $63(18.8 \%)$ \\
\hline \multicolumn{2}{|l|}{ Age at ETV } \\
\hline$<1 \mathrm{mo}$ & $8(2.4 \%)$ \\
\hline 1 to $<6$ mos & $22(6.5 \%)$ \\
\hline 6 to $<12$ mos & $21(6.2 \%)$ \\
\hline 1 to $<10$ yrs & $164(48.8 \%)$ \\
\hline$\geq 10 \mathrm{yrs}$ & $121(36.0 \%)$ \\
\hline \multicolumn{2}{|l|}{ Etiology of hydrocephalus* } \\
\hline Aqueductal stenosis & $83(24.8 \%)$ \\
\hline Midbrain tumor/lesion & $71(21.2 \%)$ \\
\hline Posterior fossa tumor & $48(14.4 \%)$ \\
\hline Other intracranial cyst & $21(6.3 \%)$ \\
\hline Post-IVH & $20(6.0 \%)$ \\
\hline Supratentorial tumor & $18(5.4 \%)$ \\
\hline Posterior fossa cyst & $9(2.7 \%)$ \\
\hline Communicating congenital & $12(3.6 \%)$ \\
\hline Myelomeningocele & $10(3.0 \%)$ \\
\hline CSF infection & $6(1.8 \%)$ \\
\hline Craniosynostosis & $6(1.8 \%)$ \\
\hline Other congenital & $1(0.3 \%)$ \\
\hline Head injury & $3(0.9 \%)$ \\
\hline Spontaneous ICH/IVH/SAH & $4(1.2 \%)$ \\
\hline Other etiology & $22(6.6 \%)$ \\
\hline \multicolumn{2}{|l|}{ ETVSS* } \\
\hline 10 & $1(0.3 \%)$ \\
\hline 20 & $1(0.3 \%)$ \\
\hline 30 & $3(0.9 \%)$ \\
\hline 40 & $9(2.7 \%)$ \\
\hline 50 & $20(6.0 \%)$ \\
\hline 60 & $24(7.2 \%)$ \\
\hline 70 & $78(23.4 \%)$ \\
\hline 80 & $123(36.8 \%)$ \\
\hline 90 & $75(22.4 \%)$ \\
\hline
\end{tabular}

$\mathrm{ICH}=$ intracerebral hemorrhage; $\mathrm{IVH}=$ intraventricular hemorrhage; $\mathrm{SAH}=$ subarachnoid hemorrhage.

* Data available in 334 patients.

2 variables were entered into a multivariate Cox regression analysis, both remained significant. For ETVSS, the estimated relative risk of failure decreased by $21 \%$ for a patient with a score 10 points higher than another (HR $0.79,95 \%$ CI $0.70-0.89, p<0.001$ ), while the estimated risk of failure was one-half for a patient in whom a naked basilar artery was visualized versus not (HR 0.50, 95\% CI 0.28-0.91, p $=0.023$ ).

The results were very similar when using survival analysis to determine predictors of ETV success at 6 months. In univariate analyses, the following had associations with $p<0.15$ : ETVSS $(p<0.001)$, ability to view a naked basilar artery $(\mathrm{p}=0.022)$, and estimated size of the ostomy ( $\mathrm{p}$ $=0.049$ ). Kaplan-Meier 6-month success rates for these factors are shown in Table 5. When all 3 variables were 
TABLE 2. Operative details in patients who underwent ETV

\begin{tabular}{|c|c|}
\hline Variable & No. of Cases (\%) \\
\hline \multicolumn{2}{|l|}{ Type of endoscope used* } \\
\hline Flexible & $36(10.8 \%)$ \\
\hline Rigid & $296(89.2 \%)$ \\
\hline Concurrent biopsy performed & $47(14.0 \%)$ \\
\hline \multicolumn{2}{|l|}{ Degree of intraop bleeding } \\
\hline None & $198(58.9 \%)$ \\
\hline Mild (did not obstruct view totally) & $118(35.1 \%)$ \\
\hline $\begin{array}{l}\text { Moderate (view totally obstructed but cleared w/ } \\
\text { in 2-3 mins) }\end{array}$ & $14(4.2 \%)$ \\
\hline $\begin{array}{l}\text { Severe (took >5 mins to return to clear working } \\
\text { condition) }\end{array}$ & $6(1.8 \%)$ \\
\hline \multicolumn{2}{|l|}{ Degree of forniceal injury† } \\
\hline No visible injury w/ fornix pristine & $267(83.4 \%)$ \\
\hline $\begin{array}{l}\text { Small, punctate contusions or subpial } \\
\text { hemorrhage(s) but ependyma intact }\end{array}$ & $41(12.8 \%)$ \\
\hline $\begin{array}{l}\text { Large confluent contusions or subpial hemor- } \\
\text { rhage but ependyma intact }\end{array}$ & $1(0.3 \%)$ \\
\hline Small breach of ependyma overlying fornix & $9(2.8 \%)$ \\
\hline Frank tear of fornix & $2(0.6 \%)$ \\
\hline Major arterial injury & $1(0.3 \%)$ \\
\hline Venous injury & $5(1.5 \%)$ \\
\hline Thalamic contusion & $6(1.8 \%)$ \\
\hline Hypothalamic contusion & $5(1.5 \%)$ \\
\hline
\end{tabular}

* Data were missing in 4 cases.

$\dagger$ Data were missing in 3 cases, and forniceal injury could not be assessed in 13 cases.

entered into a multivariate Cox regression analysis, only ETVSS (HR for 10-point increase 0.79, 95\% CI 0.69-0.90, $\mathrm{p}<0.001)$ and ability to view a naked basilar artery (HR $0.49,95 \%$ CI $0.26-0.95, \mathrm{p}=0.035)$ remained significant.

\section{Discussion}

The results of this study represent the largest prospective multicenter experience with ETV in North America to date. We have shown that serious complications from ETV are low when the procedure is performed at centers with experienced practitioners $(<2 \%$ incidence of new neurological deficit or meningitis) and that the ETVSS is the strongest predictor of ETV success. We also found that visualization of a naked basilar artery was independently associated with ETV success. The unique major strengths of this study compared with studies reported in the literature include the detailed, prospective, contemporaneous collection of intraoperative data, the relatively large sample size, and the involvement of multiple centers. These strengths increase both the internal and external validity of our results.

Recently, Bouras and Sgouros reviewed the literature to estimate ETV complications based on published case series. ${ }^{2}$ They included data from 2985 ETVs from 34 series, which represents a wide range of practice settings contributing to their summary estimates. In distinction, our series was limited to select North American academic centers. However, the vigilance of complication reporting and com-
TABLE 3. Details of fenestration of the third ventricle floor

\begin{tabular}{|c|c|}
\hline Variable & No. of Cases $(\%)$ \\
\hline Fenestration of 3rd ventricle abandoned & $25(7.4 \%)$ \\
\hline \multicolumn{2}{|l|}{ Method of initial floor penetration* } \\
\hline Monopolar cautery w/o cauterization & $39(12.6 \%)$ \\
\hline Monopolar cautery w/ cauterization & $1(0.3 \%)$ \\
\hline Bipolar cautery & $18(5.8 \%)$ \\
\hline Stylet & $167(54.0 \%)$ \\
\hline Closed forceps & $77(24.9 \%)$ \\
\hline Scissors & $4(1.3 \%)$ \\
\hline Endoscope & $3(1.0 \%)$ \\
\hline 3rd ventricle floor ballooned up after fenestration $†$ & $247(80.2 \%)$ \\
\hline Residual prepontine membranes left unopened $†$ & $63(20.4 \%)$ \\
\hline Scope guided through ostomy $\ddagger$ & $280(90.3 \%)$ \\
\hline Naked BA visualized* & $290(93.8 \%)$ \\
\hline $\begin{array}{l}\text { BA = basilar artery. } \\
\text { Data missing for } 27 \text { cases. } \\
\text { † Data missing for } 28 \text { cases. } \\
\text { † Data missing for } 26 \text { cases. }\end{array}$ & \\
\hline
\end{tabular}

plication definitions varied widely among the 34 series they included, whereas we had contemporaneously collected intraoperative data on individual patients and standard a priori definitions of complications. Therefore, our results may provide a more accurate assessment of the true incidence of ETV complications, although the applicability of our results to other practice settings may be more limited. Compared with the results of Bouras and Sgouros, our findings indicated higher rates of intraoperative bleeding $(6.0 \%$ moderate or severe bleeding compared with $3.7 \%$ "considerable intraoperative bleeding" 2 ), but the rate of major arterial injury was similar $(0.3 \%$ compared with $0.2 \%)$. This result is probably attributable to our ability to more carefully document less severe intraoperative bleeding episodes. It also explains why our data demonstrate much higher rates of forniceal (16.6\%), hypothalamic (1.5\%), and thalamic $(1.8 \%)$ injury than did the data of Bouras and Sgouros, who reported a combined incidence of only $0.24 \%$. The relatively high rate of forniceal injury, in particular, is a novel finding of our study. Although virtually all such injuries resulted in

TABLE 4. Postoperative complications in 204 patients

\begin{tabular}{lc}
\hline \multicolumn{1}{c}{ Complication } & No. of Cases (\%) \\
\hline CSF leak & $9(4.4 \%)$ \\
\hline Hyponatremia & $8(3.9 \%)$ \\
\hline Pseudomeningocele & $8(3.9 \%)$ \\
\hline Seizure & $4(2.0 \%)$ \\
\hline Meningitis & $3(1.5 \%)$ \\
\hline New neurological deficit & $3(1.5 \%)$ \\
\hline Temporary & $2(1.0 \%)$ \\
\hline Permanent & $1(0.5 \%)$ \\
\hline IVH & $1(0.5 \%)$ \\
\hline Wound infection & $1(0.5 \%)$ \\
\hline Urinary tract infection & $1(0.5 \%)$ \\
\hline
\end{tabular}




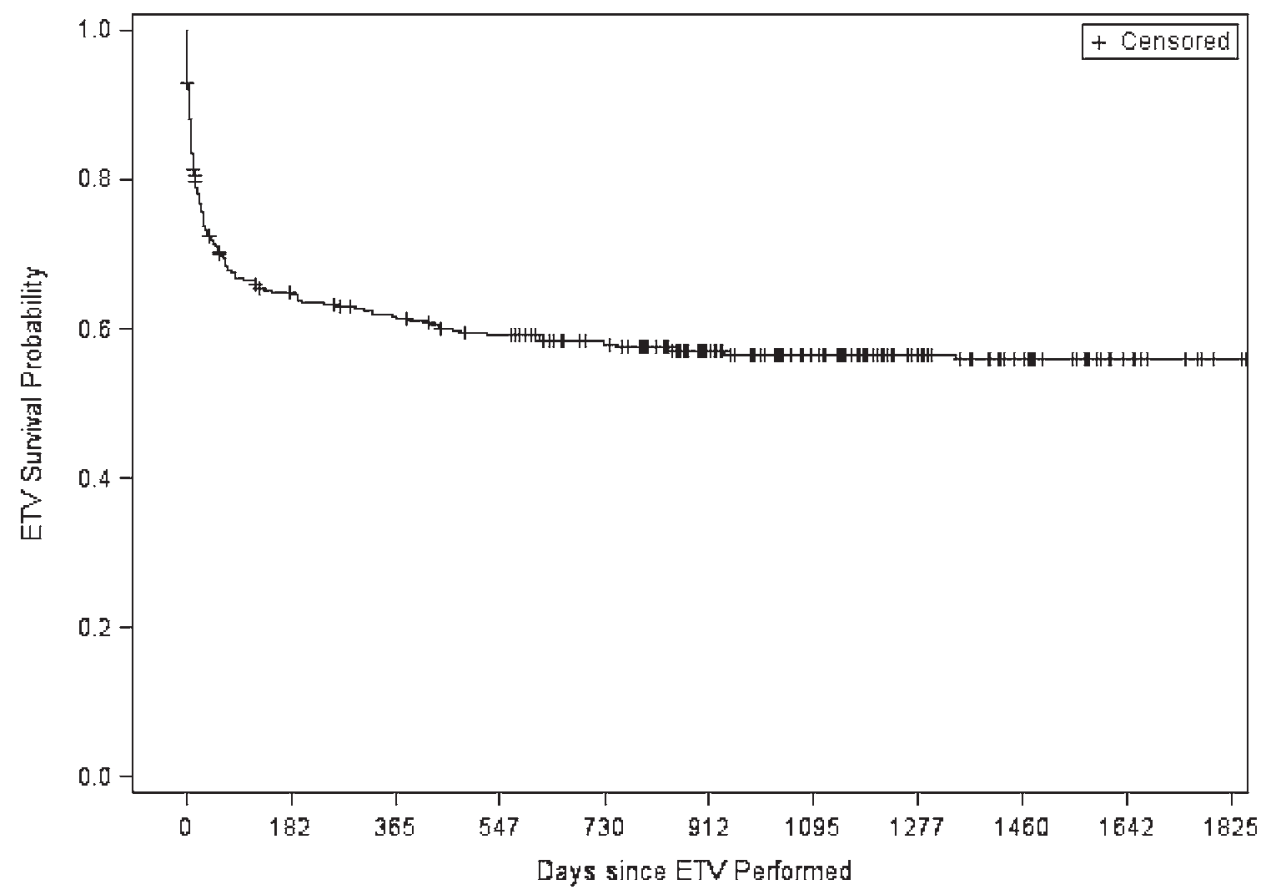

FIG. 1. Survival curve showing time to first ETV failure.

no obvious postoperative deficit, we cannot exclude the possibility that these injuries may adversely, albeit subtly, affect cognitive function. This matter should be a focus of further work. With respect to clinically relevant postoperative complications, our incidence of meningitis (1.5\%) was similar to that in the Bouras and Sgouros study $(1.8 \%)$, but we noted a higher incidence of CSF leak (4.4\% vs $1.6 \%)$ and a lower incidence of permanent neurological deficit ( $0.5 \%$ vs $1.4 \%$ ).

Predicting ETV success is important in helping to select appropriate candidates for the procedure and to counsel

TABLE 5. Success of ETV based on ETVSS and intraoperative factors

\begin{tabular}{lcc}
\hline \multicolumn{1}{c}{ Variable } & $\begin{array}{c}\text { No. of Cases } \\
(\% \text { available } \\
\text { cases })\end{array}$ & $\begin{array}{c}\text { 6-Mo Kaplan- } \\
\text { Meier Success } \\
\text { Rate }(\%)\end{array}$ \\
\hline ETVSS $(\mathrm{n}=334)$ & $14(4.2 \%)$ & \\
\hline$\leq 40$ & $122(36.5 \%)$ & $52.2 \%$ \\
\hline $50-70$ & $198(59.3 \%)$ & $75.9 \%$ \\
\hline$\geq 80$ & $19(6.1 \%)$ & \\
\hline Able to view naked BA $(\mathrm{n}=309)$ & $47.4 \%$ \\
\hline No & $290(93.9 \%)$ & $71.7 \%$ \\
\hline Yes & & \\
\hline $\begin{array}{c}\text { Estimated size of 3rd ventricle } \\
\text { floor ostomy }(\mathrm{n}=305)\end{array}$ & $39(12.8 \%)$ \\
\hline$<4 \mathrm{~mm}$ & $148(48.5 \%)$ & $68.9 \%$ \\
\hline 4 to $<6 \mathrm{~mm}$ & $84(27.5 \%)$ & $70.9 \%$ \\
\hline 6 to $<8 \mathrm{~mm}$ & $34(11.1 \%)$ & $85.2 \%$ \\
\hline$\geq 8 \mathrm{~mm}$ & &
\end{tabular}

$\mathrm{n}=$ number of patients. families about the merits of ETV relative to shunting. ${ }^{13,14}$ The ETVSS has been shown to predict, with reasonable accuracy, the chances of ETV success using only preoperative data (patient age, etiology of hydrocephalus, and history of a previous shunt $)^{15}$ and has been independently validated in many settings around the world. ${ }^{1,3,5,7,8,16,18,24}$ Other means of predicting ETV success have also been postulated, including preoperative predictors, ${ }^{1}$ radiological predictors,${ }^{6}$ and intraoperative predictors. ${ }^{9}$ We found, on univariate analysis only, that a larger ostomy size and the presence of a naked basilar artery were predictive of 6-month ETV success. On multivariate analyses, however, only the ETVSS and a naked basilar artery remained as significant predictors. We note that Kombogiorgas and Sgouros did not find any intraoperative predictors of ETV success in a small sample of 33 patients in whom operative videos were reviewed. ${ }^{10}$ Despite this, however, it is possible that some other intraoperative predictors exist beyond visualization of the naked basilar artery (especially since the trend shown in Table 5 for ostomy size is compelling), but the limitations of our study obscured our ability to detect them. For example, we did not establish the degree of interobserver reliability in our intraoperative variables, for example, a surgeon's estimate of ostomy size, the presence of residual prepontine membranes, or ballooning of the third ventricle floor. All of these are fairly subjective, and any lack of reliability in measuring these variables would attenuate the true relationship that may exist with ETV success. Moreover, we did not include as one of our variables the presence of pulsations at the third ventricle floor after ETV completion, as had been suggested by Greenfield et al. ${ }^{9}$ Instead, we tried to capture the concept of this variable, that is, the assessment of flow through the ostomy, by looking for any ballooning of the third ventricle floor after ostomy creation. Another 
limitation is the relative lack of heterogeneity in some of our intraoperative variables. For example, in fewer than $10 \%$ of patients a scope could not be guided through the ostomy. In only about $20 \%$ were there residual prepontine membranes or a third ventricle floor that did not balloon up after ostomy creation. The relatively low incidence of these events is probably attributable to selecting patients with anatomy most favorable for ETV combined with the experience of the surgeons involved, all of whom are fulltime pediatric neurosurgeons at fellowship training centers. Regardless, it can be difficult to identify, for variables with such little heterogeneity, a true association with outcome.

An added feature of our data is that they provide a snapshot of the current state of how ETV is used in North America. Specifically, a review of patient characteristics reveals that the majority of patients chosen for ETV were generally expected to have a reasonably high chance of success, with little evidence of extending traditional indications. For example, infants under 1 year of age accounted for only $15.2 \%$ of the sample, and the ETVSS was $\geq 70$ in $83 \%$ of the patients. These figures portray a relatively conservative approach in the use of ETV. While this approach represents an accurate picture of the current practice pattern for ETV in North America, it does not include the impact that the addition of CPC may bring., ${ }^{4,17,23,26,27,28}$ The addition of CPC could expand the patient base for ETV to include more infants (with lower ETVSS), but its role in North America needs further study. In the HCRN, we are currently enrolling infants in a prospective study of ETV+CPC to better define the indications for this procedure.

We recognize important limitations to our study in addition to those already mentioned. For example, patient selection and the determination of ETV failure and complications were decided entirely by the treating surgeon, without independent adjudication. The failure of ETV is often hard to define since ventricle size is known to remain large even in seemingly successful cases.12,21,22 Although the impact of persistently enlarged ventricles on long-term outcome is still a point of debate,,$^{11,19,25}$ the tolerance for larger ventricles does result in different standards for declaring treatment failure compared with shunt failure. Treating surgeons may also have a natural tendency to under-report complications. We tried to mitigate this factor by ensuring that trained research coordinators who were independent of the clinical team captured the data on complications. Regardless, independent review of outcomes would have strengthened our results. Another issue with our study is the limited sample size. Although we performed a rather large series, a further substantial increase in sample size would have ensured more accurate estimates of complications, especially those that are rare. We, therefore, acknowledge that further prospective data collection is necessary, and this will be continued by the HCRN.

\section{Conclusions}

Our reported experience represents the most detailed account of results of ETV in North America and provides the most accurate picture to date of ETV success and complications. Serious complications are uncommon. In addition to the ETVSS, visualization of a naked basilar artery was predictive of ETV success. Further prospective work is needed to address some of the limitations of our study and will be performed by the HCRN.

\section{Appendix}

\section{Hydrocephalus Clinical Research Network Members}

The HCRN currently consists of the following clinical centers and investigators: Primary Children's Hospital, University of Utah (J. Kestle); Children's Hospital of Alabama, University of Alabama at Birmingham (J. Oakes, C. Rozzelle); Hospital for Sick Children, University of Toronto (J. Drake, A. Kulkarni); Texas Children's Hospital, Baylor College of Medicine (T. Luerssen, W. Whitehead); Seattle Children's Hospital, University of Washington (S. Browd, T. Simon); Children's Hospital of Pittsburgh, University of Pittsburgh (M. Tamber); St. Louis Children's Hospital, Washington University in St. Louis (D. Limbrick); Monroe Carell Jr. Children's Hospital at Vanderbilt, Vanderbilt University Medical Center (J. Wellons, R. Naftel, C. Shannon); British Columbia Children's Hospital, University of British Columbia (D. Cochrane); HCRN Data Coordinating Center, Department of Pediatrics, University of Utah (R. Holubkov, J. Riva-Cambrin).

\section{Acknowledgments}

We thank our colleagues who kindly agreed to participate in this HCRN project and allow the collection of patient data for the purpose of this publication: D. Brockmeyer, M. Walker, R. Bollo, J. Blount, J. Johnston, B. Rocque, L. Ackacpo-Satchivi, P. Dirks, J. Rutka, M. Taylor, D. Curry, R. Dauser, A. Jea, S. Lam, R. Ellenbogen, J. Ojemann, A. Lee, A. Avellino, I. Pollack, S. Greene, E. Tyler-Kabara, T. S. Park, J. Leonard, M. Smyth, N. Tulipan, A. Singhal, and P. Steinbok.

In addition, this work would not have been possible without the outstanding support of the dedicated personnel at each clinical site and the data coordinating center. Special thanks goes to N. Tattersall (Salt Lake City), A. Arynchyna (Birmingham), H. Ashrafpour (Toronto), S. Ryan (Houston), A. Anderson (Seattle), K. Diamond (Pittsburgh), D. Mercer (St. Louis), S. Gannon (Nashville), A. Cheong (British Columbia), and M. Langley, N. Nunn, R. Reeder, V. Friemann, and J. Alvey (Utah Data Coordinating Center).

The HCRN has been funded by the National Institute of Neurological Disorders and Stroke (NINDS Grant No. 1RC1NS06894301), Patient Centered Outcome Research Institute (PCORI Grant No. CER-1403-13857), The Gerber Foundation (Reference No. 1692-3638), private philanthropy, and the Hydrocephalus Association.

Dr. Simon was supported by Award No. K23NS062900 from the National Institute of Neurological Disorders and Stroke and the Seattle Children's Center for Clinical and Translational Research, as well as the Clinical and Translational Science Award Grant No. ULI RR025014 from the National Center for Research Resources, a component of the National Institutes of Health.

\section{References}

1. Azimi P, Mohammadi HR: Predicting endoscopic third ventriculostomy success in childhood hydrocephalus: an artificial neural network analysis. J Neurosurg Pediatr 13:426-432, 2014

2. Bouras T, Sgouros S: Complications of endoscopic third ventriculostomy. J Neurosurg Pediatr 7:643-649, 2011

3. Breimer GE, Sival DA, Brusse-Keizer MGJ, Hoving EW: An external validation of the ETVSS for both short-term and long-term predictive adequacy in 104 pediatric patients. Childs Nerv Syst 29:1305-1311, 2013

4. Chamiraju P, Bhatia S, Sandberg DI, Ragheb J: Endoscopic third ventriculostomy and choroid plexus cauterization in 
posthemorrhagic hydrocephalus of prematurity. J Neurosurg Pediatr 13:433-439, 2014

5. Durnford AJ, Kirkham FJ, Mathad N, Sparrow OC: Endoscopic third ventriculostomy in the treatment of childhood hydrocephalus: validation of a success score that predicts long-term outcome. J Neurosurg Pediatr 8:489-493, 2011

6. Foroughi M, Wong A, Steinbok P, Singhal A, Sargent MA, Cochrane DD: Third ventricular shape: a predictor of endoscopic third ventriculostomy success in pediatric patients. J Neurosurg Pediatr 7:389-396, 2011

7. Furlanetti LL, Santos MV, de Oliveira RS: The success of endoscopic third ventriculostomy in children: analysis of prognostic factors. Pediatr Neurosurg 48:352-359, 2012

8. García LG, López BR, Botella GI, Páez MD, da Rosa SP, Rius F, et al: Endoscopic Third Ventriculostomy Success Score (ETVSS) predicting success in a series of 50 pediatric patients. Are the outcomes of our patients predictable? Childs Nerv Syst 28:1157-1162, 2012

9. Greenfield JP, Hoffman C, Kuo E, Christos PJ, Souweidane MM: Intraoperative assessment of endoscopic third ventriculostomy success. J Neurosurg Pediatr 2:298-303, 2008

10. Kombogiorgas D, Sgouros S: Assessment of the influence of operative factors in the success of endoscopic third ventriculostomy in children. Childs Nerv Syst 22:1256-1262, 2006

11. Kulkarni AV, Donnelly R, Mabbott DJ, Widjaja E: Relationship between ventricular size, white matter injury, and neurocognition in children with stable, treated hydrocephalus. J Neurosurg Pediatr 16:267-274, 2015

12. Kulkarni AV, Drake JM, Armstrong DC, Dirks PB: Imaging correlates of successful endoscopic third ventriculostomy. J Neurosurg 92:915-919, 2000

13. Kulkarni AV, Drake JM, Kestle JR, Mallucci CL, Sgouros S, Constantini S: Endoscopic third ventriculostomy vs cerebrospinal fluid shunt in the treatment of hydrocephalus in children: a propensity score-adjusted analysis. Neurosurgery 67:588-593, 2010

14. Kulkarni AV, Drake JM, Kestle JRW, Mallucci CL, Sgouros S, Constantini S: Predicting who will benefit from endoscopic third ventriculostomy compared with shunt insertion in childhood hydrocephalus using the ETV Success Score. J Neurosurg Pediatr 6:310-315, 2010

15. Kulkarni AV, Drake JM, Mallucci CL, Sgouros S, Roth J, Constantini S: Endoscopic third ventriculostomy in the treatment of childhood hydrocephalus. J Pediatr 155:254-259, 259.e1, 2009

16. Kulkarni AV, Riva-Cambrin J, Browd SR: Use of the ETV Success Score to explain the variation in reported endoscopic third ventriculostomy success rates among published case series of childhood hydrocephalus. J Neurosurg Pediatr 7:143-146, 2011

17. Kulkarni AV, Riva-Cambrin J, Browd SR, Drake JM, Holubkov R, Kestle JRW, et al: Endoscopic third ventriculostomy and choroid plexus cauterization in infants with hydrocephalus: a retrospective Hydrocephalus Clinical Research Network study. J Neurosurg Pediatr 14:224-229, 2014

18. Naftel RP, Reed GT, Kulkarni AV, Wellons JC: Evaluating the Children's Hospital of Alabama endoscopic third ventriculostomy experience using the Endoscopic Third Ventriculostomy Success Score: an external validation study. J Neurosurg Pediatr 8:494-501, 2011

19. Nikas DC, Post AF, Choudhri AF, Mazzola CA, Mitchell L, Flannery AM: Pediatric hydrocephalus: systematic literature review and evidence-based guidelines. Part 10: Change in ventricle size as a measurement of effective treatment of hydrocephalus. J Neurosurg Pediatr 14 (Suppl 1):77-81, 2014

20. Rasul FT, Marcus HJ, Toma AK, Thorne L, Watkins LD: Is endoscopic third ventriculostomy superior to shunts in patients with non-communicating hydrocephalus? A systematic review and meta-analysis of the evidence. Acta Neurochir (Wien) 155:883-889, 2013
21. Romeo A, Naftel RP, Griessenauer CJ, Reed GT, Martin R, Shannon CN, et al: Long-term change in ventricular size following endoscopic third ventriculostomy for hydrocephalus due to tectal plate gliomas. J Neurosurg Pediatr 11:20-25, 2013

22. St George E, Natarajan K, Sgouros S: Changes in ventricular volume in hydrocephalic children following successful endoscopic third ventriculostomy. Childs Nerv Syst 20:834-838, 2004

23. Stone SSD, Warf BC: Combined endoscopic third ventriculostomy and choroid plexus cauterization as primary treatment for infant hydrocephalus: a prospective North American series. J Neurosurg Pediatr 14:439-446, 2014

24. Vogel TW, Bahuleyan B, Robinson S, Cohen AR: The role of endoscopic third ventriculostomy in the treatment of hydrocephalus. J Neurosurg Pediatr 12:54-61, 2013

25. Warf B, Ondoma S, Kulkarni A, Donnelly R, Ampeire M, Akona J, et al: Neurocognitive outcome and ventricular volume in children with myelomeningocele treated for hydrocephalus in Uganda. J Neurosurg Pediatr 4:564-570, 2009

26. Warf BC: Comparison of endoscopic third ventriculostomy alone and combined with choroid plexus cauterization in infants younger than 1 year of age: a prospective study in 550 African children. J Neurosurg 103 (6 Suppl):475-481, 2005

27. Warf BC, Campbell JW, Riddle E: Initial experience with combined endoscopic third ventriculostomy and choroid plexus cauterization for post-hemorrhagic hydrocephalus of prematurity: the importance of prepontine cistern status and the predictive value of FIESTA MRI imaging. Childs Nerv Syst 27:1063-1071, 2011

28. Zandian A, Haffner M, Johnson J, Rozzelle CJ, Tubbs RS, Loukas M: Endoscopic third ventriculostomy with/without choroid plexus cauterization for hydrocephalus due to hemorrhage, infection, Dandy-Walker malformation, and neural tube defect: a meta-analysis. Childs Nerv Syst 30:571-578, 2014

\section{Disclosures}

Dr. Browd is a cofounder of and has equity and stock options in Aqueduct Neurosciences Inc., Aqueduct Critical Care Inc., and Navisonics Inc., all of which are unrelated to the current study. Dr. Limbrick receives support for basic science research efforts from Medtronic, Inc., and Karl Storz, Inc., unrelated to the current study. None of the sponsors participated in the design and conduct of this study; collection, management, analysis, and interpretation of the data; or preparation, review, or approval of this manuscript. Its contents are solely the responsibility of the authors and do not necessarily represent the official view of the sponsors.

\section{Author Contributions}

Conception and design: Kulkarni, Riva-Cambrin, Wellons, Whitehead, Kestle. Acquisition of data: Kulkarni, Riva-Cambrin, Browd, Drake, Limbrick, Rozzelle, Simon, Tamber, Wellons, Whitehead, Kestle. Analysis and interpretation of data: Kulkarni, Riva-Cambrin, Kestle. Drafting the article: Kulkarni, Riva-Cambrin, Wellons, Whitehead, Kestle. Critically revising the article: Kulkarni, Riva-Cambrin, Holubkov, Cochrane, Drake, Limbrick, Rozzelle, Simon, Tamber, Wellons, Whitehead, Kestle. Reviewed submitted version of manuscript: all authors. Approved the final version of the manuscript on behalf of all authors: Kulkarni. Statistical analysis: Kulkarni, Holubkov. Study supervision: Kulkarni, Kestle.

\section{Correspondence}

Abhaya V. Kulkarni, Division of Neurosurgery, Hospital for Sick Children, Rm. 1503, 555 University Ave., Toronto, ON M5G 1X8, Canada. email: abhaya.kulkarni@sickkids.ca. 